\title{
LEGAL CONSCIOUSNESS AND LEGAL CULTURE IN THE ERA OF TOTAL DIGITALIZATION: THEORETICAL- METHODOLOGICAL AND LEGAL-TECHNICAL PROBLEMS
}

\author{
Pavel P. Baranov. ${ }^{1}$ \\ Alexey Y. Mamychev. ${ }^{2}$ \\ Roman I. Dremliuga ${ }^{3}$ \\ Olga I. Miroshnichenko ${ }^{4}$
}

\begin{abstract}
The paper analyses the change in ideas about law in the digitalization era. Noting the insufficient theoretical substantiation of attempts to impose on modern law any special characteristics arising from the widespread development of digital technologies, the authors admit that in the era of virtual reality, the laws of the digital virtual world begin to actively compete with the laws of nature. This entails a slight decrease in the role of law as a traditional regulator of social relationships. However, according to the authors, one should not artificially diminish the role of law even in the era of digitalization. In
\end{abstract} this regard, the paper discusses the main trends in the study of legal digitalization processes. The first trend is due to the need to promptly respond by legal means to the emergence of new areas of legal regulation caused by the widespread use of digital information technologies. The second trend assumes the expansion and rethinking of the subject and object of legal science within the context that new digital "participants" of legal relations born due to intelligent human activity emerge. In this regard, the authors dwell on the most relevant conceptual and practical problems of using digital technologies in the processes of law

\footnotetext{
${ }^{1}$ Doctor habil. in law, professor, head of department of constitutional and municipal law, RANEPA under the President of the Russian Federation, South Russian institute of management, Rostov-on- Don, Russia.email: pravosoznanie@gmail.com https://orcid.org/0000-0001-7062-5266.

${ }^{2}$ Doctor habil. in political science, $\mathrm{PhD}$ in legal science, Head of the political and legal research laboratory, Lomonosov Moscow State University; Professor, Vladivostok State University of Economics and Service mamychev@yandex.ruORCID 0000-0003-1325-7967

${ }^{3} \mathrm{PhD}$ in law, Associate Professor, School of Law, Far Eastern Federal University, Vladivostok, Russia E-mail: dreamluck@yandex.ru https://orcid.org/0000-0001-9751-7572

${ }^{4}$ School of Law, Far Eastern Federal University, Vladivostok, Russia; PhD in Law, L1.M. in legal theory, Associate Professor, Department of theory and history of state and law, Russia, Vladivostok, Sukhanova st. 8, ORCID 0000-0002-7606-4444, E-mail: olga-star.05@mail.ru
} 
education and law enforcement within the context of various approaches to legal thinking. Special attention is paid to the institution of digital (informational) rights and freedoms of citizens, as well as "traditional" individual rights in the new digital virtual reality. The paper draws conclusions about the possibilities and prospects of further legal regulation in the sphere of digital (information) legal relations and artificial intelligence, as well as the influence of information technology development processes on legal processes in general.

Keywords: virtual reality; artificial intelligence; information and digital technologies; legal understanding; legal awareness; digital (information) rights; digitalization of law; e-democracy.

\section{INTRODUCTION}

Changing ideas about law in the era of digitalization is an urgent problem, undoubtedly one that deserves the most close attention and study. Noting the insufficient theoretical substantiation of attempts to connect most of the problems of modern legal consciousness with the rapid onset of the era of information technology, one cannot but admit that the partial transformation of ideas about law is still a derivative of the endless process of digital (information) innovations of recent decades. The purpose of this paper is to study digitalization processes within the context of their impact on legal consciousness both at the everyday and at the professional levels.

Recognizing a slight decrease in the role of law as a traditional regulator of public relations in the era of digital technologies and virtual reality, the authors argue that artificially diminishing its role means taking wishful thinking. The rapid informatization processes have seriously reformatted the everyday idea of the surrounding world and legal reality. This fact only actualizes the problems of optimal use of traditional legal means and methods of influencing the world around. The emergence of new areas of legal regulation poses new tasks for the law; however, their solution should be based on traditional general legal approaches.

Any discussions about the decline of the idea of law, classical lawmaking and law enforcement in the era of digitalization do not have any 
serious ground today. It is clearly premature to talk about digital law (not in the sense of the relevant and only emerging branch of law), as well as about digital legal consciousness or new self-sufficient institutional formations. However, it is still worth paying attention to the main problems in the field of law and legal consciousness that have generated the digitalization processes.

In addition, one of the advantages of general theoretical legal science has always been proactive work. To be ready for the possible challenges of the new digital era means to adequately assess all the innovations, dangers and risks that modern information technologies carry for law and legal awareness. At the same time, one cannot fail to notice a significant optimization of various legal processes, which is a consequence of the reasonable and proportionate use of digital information technologies in the legal sphere.

The main stages of digitalization of law and legal activity

The processes of digitalization in various spheres of society's life today are a key development benchmark and the main trend in optimizing public power activities. These processes are ambiguous and have different stages and characteristics that should be taken into account when describing the degree of their influence on the legal consciousness of citizens and the legal culture of society. In this regard, there can be distinguished three stages and, accordingly, levels or depth of the digital transformation of public relations (Baranov., Mamychev;2020, Mamychev., Kim Frolova, 2020).

The first stage from which the process of digital transformation of public relations begins is associated with the automation of routine operations. This is the so-called superficial and purely external impact of innovative digital technologies on a particular sphere of society's life. It proves that technological solutions solve a number of technical and routine operations that free up time for high-quality human activities. In other words, digital and robotic technologies are being developed and implemented to replace the same type of routine, manual, production, office and other labour. This external and pinpoint digitalization of professional activity has very little effect on the essence and content of a specific activity, 
its social purpose, functionality and institutionalization of the professional environment. Nevertheless, it already provides some "presence" of technologies in professional activities, gradually forming certain bonds and connections between technologies and people. As modern philosophers note: "Instruments of labour exist only in relation to the mixtures that they make possible or that make them possible. The stirrup entails a new symbiosis of man and horse, which at the same time entails new weapons and new tools. Instruments of labour are inseparable from symbiosis or mergers that determine machine assembly, Nature - Society" (Deleuze. Guattari, 2010) The first stage thereby forms the prerequisites for close interaction and integration of man and new technologies, forming new images, meanings, guidelines, which will subsequently lead to paradigmatic shifts.

The second stage is associated with innovative algorithmic solutions that are focused on the development and operation of autonomous expert and analytical digital systems that collect a colossal amount of information, process it and use it for making management decisions. This stage was associated with the development of autonomous systems and digital algorithms that provide advisory functions. During this period, the imagination drew pictures of "mixed, human and automated teams", which work to achieve fundamentally new goals, but "set exclusively by the people who are part of those teams" (Delanda,2014 p. 249).

This stage is interpreted not only from the standpoint of the quantitative introduction of certain innovations, but already in the aspect of a qualitative change in professional activity. Nevertheless, the latter is presented as the next stage in the improvement of human tools that continue and (or) functionally replace him (a man). In this case, the autonomy of these technologies is allowed at an advisory, auxiliary, or providing level, i.e. functioning in an instrumental mode. At the same time, a person has a "fundamental right" to make decisions and implement administrative functions (Delanda, 2014)

Such an instrumental attitude towards digital technologies is characteristic of the doctrinal and legal and regulatory level for regulation of the public relation development. Today it manifests itself in many strategic documents, conventions, agreements, 
declarations, model normative legal acts, ethical standards, etc. For example, the program document "Initiatives of France in the field of robotics" considers artificial intelligence systems and robotic technologies as factors of industrial and technological progress allowing them to ensure the country's leadership and advantage, comfort and usefulness for humans (Initiatives of France in the field of robotics. March 2013). The European Declaration on Cooperation in the Field of Artificial Intelligence also quite clearly traces the distinction between humans and technologies, as well as their instrumental significance in social systems: "Ensure that humans retain a key role in the development, application and decision-making process in relation to $\mathrm{AI}$, preventing actions aimed to create or use malicious solutions based on AI" (Declaration on cooperation in the field of artificial intelligence (04/10/2018).

Representatives of legal science make a special emphasis on the instrumental nature of the development of modern digital technologies. The most frequently discussed issues in this regard include protection of intellectual rights, safety of personal data, ways to automate lawmaking and law enforcement
(Mamychev., Miroshnichenko;2019, Larina., Ovchinsky, 2018). modernization of public administration and impact methods, ways to protect digital public infrastructure, etc. (Zorkin;2018, Kartskhia, 2017). In the context of the growing ambitions of the state in the sphere of control of the virtual space, special attention is paid to issues related to ensuring the inviolability of the private virtual life of citizens, the secrecy of correspondence, telephone conversations, freedom of speech on the Internet, etc. (The world in the digital age: politics, law, economics in the XXI century: monograph. M .: Publishing centre RIOR, 2020; Robots claim their rights: doctrinal and legal foundations and moral and ethical standards for the use of autonomous robotic technologies and devices: monograph. Moscow: Publishing Centre RIOR, 2020).

The third stage is associated with a qualitative transformation of both public relations themselves and professional thought activity under the influence of the introduction of end-toend digital technologies. It is associated with the transfer of administrative (executive) functions to machines and complex algorithms; more precisely, 
when performing complex tasks upon processing various data, modelling various scenarios and calculating possible response trajectories, automated algorithms and artificial intelligence systems imperceptibly crossed the line between a purely expert, deliberative mode of functioning and implementation of administrative functions.

For the first time, the sphere of military developments and systems of automated control over law enforcement emerges where there is a blurring of the line and boundaries between the deliberative and administrative modes of functioning of "machines" (as a collective image of all modern end-toend digital technologies).

In the first case, we can refer to the research of M. DeLand, who notes that "the distinction between deliberative and managerial (executive) abilities is erased in various applications of artificial intelligence (AI). Perhaps the best example of the disappearing distinction between the purely deliberative and managerial role of computers can be found in the field of war games ... the conclusions obtained from the observations of simulated armageddons arranged by combat robots (computer simulations of the third world war and other military conflicts authors) even entered into strategic doctrines and contingency plans; we can say that these "robotic events" have already begun to blur the line between the purely advisory and managerial role of smart machines" (elanda,2014 p. 7)

In the second case, we can give the example of A. Greenfield, who describes it as follows: "With regard to the maintenance of public order, this system is called predicative policing. The idea is that, having at their disposal only one, but rather rich array of data on past incidents, law enforcement agencies will be more likely to predict in advance the places of crime and even the identity of criminals and prevent any real offenses"( Greenfield,2018. p. ... 303).

In general, the era of digital transformation of society, law and state is not just the introduction of a number of innovative technologies to facilitate our life, optimize public administration, facilitate the functioning of legal activities, etc. This is mainly a qualitative change in society, the transformation of its paradigmatic foundations, value-normative guidelines and attitudes, spiritual and moral standards and requirements (Baranov., Mamychev., Mordovtsev,2019). In 
modern specialized literature, digitalization is an analytical concept that reflects these cardinal changes in the overwhelming majority of cases. D. Bell is right in this regard when he noted that a similar concept of "post-industrial society is an analytical construction, and not a picture of a specific or concrete society. It is a kind of paradigm, a social scheme that reveals new axes of social organization and stratification in a developed society" (Bell,2004 p. XCVII).

In a similar way, we can also characterize the digitalization of legal reality, which reflects not so much the introduction of individual technologies or algorithmic solutions to optimize legal practice, facilitate the functioning of a justice system or the introduction of automated complexes based on the artificial intelligence system in ensuring law and order, but qualitative changes in the legal consciousness of citizens and the legal culture of society as a whole. The data given to the process essentially change the nature and forms of social relations, their direction and valuenormative orientation. It is from this perspective that we propose to consider the stated problems in this work.
Theoretical and legal approaches to the transformation of legal consciousness

In legal science, several basic general theoretical conceptual approaches to understanding legal consciousness have developed: historical, philosophicalepistemological, sociological, formallogical and structural-functional, within which more than 250 definitions have been developed. Traditionally, legal consciousness is considered as a system of ideas, perceptions, feelings, views, emotions that characterize the attitude of people and their communities to previously acting, currently existing and desired legally significant phenomena, processes and states. It is legal consciousness that acts as an internal determinant of any activity related to jurisprudence (Borulenkov,2014 p. 366368).

A huge number of works by both contemporary authors and representatives of the classical philosophical and legal directions of the past are devoted to the peculiarities of legal consciousness. So, for example, N.A. Berdyaev characterized Russia as the most stateless and most anarchist country in the world, the Russian people 
as the most apolitical people, and anarchism as a manifestation of the Russian spirit. According to the scientist, the Russian people do not want freedom in the state, but freedom from the state (Berdyaev,1990 p. 4-5).

The famous Russian philosopher I.A. Ilyin separated the legal consciousness of the "Russian common people" and the Russian "intellectual legal consciousness" from each other. He noted that throughout the history of Russia, "the Russian common people have never lost their inclination to oppose the burdensome law with their own illegal or illicit initiative", and "legal consciousness of the Russian people, succumbing to the confusion of "curvature" and "theft", celebrated the holiday of omnipotence, revenge and self-enrichment" in conditions of political and property redistribution (Ilyin,2008. p. 95-96).

In due time, the authors of this paper devoted a significant amount of scientific research to the problems of legal consciousness and legal culture. Recently, an increasing number of works have been devoted to the socio-cultural characteristics of the Russian legal consciousness. This issue has found its wide coverage not only in the theory and philosophy of law, but also in constitutional and legal studies focused on the study of constitutional legal consciousness (Shchepachev,2019. p.1619), constitutional (constitutional-legal) culture (Barinov, p. 10-13), protection of constitutional identity (Zorkin,2019. p. 248-304), constitutional sovereignty and constitutional security (Bondar,2018 p. 6-15).

In modern studies, the Russian legal consciousness is traditionally characterized as partially undeveloped, unformed and "immature", featuring its fragmentation and contradiction. This contradiction is based on the predominance of ethicocentric principles in the legal system of views. Understanding of law in close combination with morality, ethic and, in some cases, with religion, made the legal consciousness of Russians extremely subjective and heterogeneous.

The categories of a moral and ethical nature (ideas of higher justice) ultimately did not find their proper coexistence with the categories of formal (positive, derived from the state) law, which led to a natural transformation of legal consciousness towards its deformation and the widespread development of legal nihilism. 
And if in the days of the former USSR, legal nihilism was more characterized by a completely understandable legal apathy, today it has been supplemented by a rather radical critical attitude to law as an instrument of obtaining certain political and personal dividends, including by turning to the sphere of public administration for limited category of people.

In accordance with traditional Marxist ideas, citizens continue to consider law as a way to establish the power of one class over another, one of the ways to derive personal economic benefit from the political elite, officials and other subjects of public, political, social, and economic life, which are close to power.

We must agree with the scholars who argue that "any crisis of legal consciousness is, first of all, the result of the prevalence of meaninglessness and devaluation of law over the processes of its semantic and value formation", the discrepancy between expectations from law and the result obtained, which is why legal reality is delegitimized and is perceived as "an alien reality given from the outside" (Shugurov, 2016.p. 79-80).
Another rapidly changing side of modern legal life, which is not directly tied to the critical attitude of citizens towards state power and ways of interacting with the latter, is characterized by an ever-increasing invasion of digital (information) technologies into the legal sphere, which also entails some change in ideas about law, its regulatory opportunities, the status of its subjects, etc. As rightly noted by most researchers, digitalization is an interdisciplinary problem; therefore, the degree of its mediation by representatives of various industrial sciences varies significantly.

In addition, modern legal studies of digitalization processes sin with some unsystematicity and surface (Gaivoronskaya. Miroshnichenko,2019. p. 28). One should agree with the last statement. The search for available methodological means of studying the problems of legal digitalization is still ongoing. The limits and nature of the respective discussions, the issues requiring priority comprehension, as well as the degree of their novelty and relevance are not quite clear.

Representatives of general theoretical science are in the greatest confusion in this regard, while 
representatives of industrial sciences are concerned primarily with the desire to timely regulate (often excessively) new spheres of social relations generated by the phenomenon of digitalization. In this regard, we can talk about a kind of competition; so, almost simultaneously, the category of "digital rights" was proposed by representatives of both constitutional (Nevinsky.2019, p. 26-32) and civil science (Yatsenko,2019. p.1114)

As a result, the interpretation of "digital" rights proposed by civil lawyers became the "official" (at the level of a legislative act) one. Constitutionalists, however, have to operate with the category of "information rights" or, speaking about the idea of "digital rights" (the right to access the Internet, the right to digital oblivion, the right to the inviolability of digital life, etc.), each time to specify that this category is used in a meaning that differs from the official legal interpretation. In fairness, we note that some authors began to define the corresponding group of rights as informational since before the moment when representatives of civil science reserved the category of "digital rights" for themselves (Kolesnikov.2019, p. 1316). However, the last remark does not solve the corresponding problem, since the category "information law" is also already reserved and scientific research of "digital law" is being conducted in the context of considering the problems of "information law" (Tanimov., Shevchenko, 2019.p. 6-9)

It is indicative that, rather controversial terms of "digital ecosystem" and "ecosystem of the digital economy" have begun to assert themselves in modern legal science and legislation. The use of the category "ecosystem" in the meaning of "selfsufficient virtual-digital space" in every day and pseudo-scientific speech is associated with the rapid spread of digital information communication devices, when linking to one identifier account provides constant access to personal digital information space, including on various devices.

Such an identification of the surrounding natural and digital reality, which received a subjective identification at the level of everyday consciousness, is quite understandable. However, as we have already noted, this identification began to be used not only in legal science (Gavrilov., Volodina,2019. p. 156-166), but also in legal acts (Strategy for the Development 
of the Information Society in the Russian Federation for 2017 - 2030, the Strategy for the Development of the Customs Service of the Russian Federation until 2030, etc.), which raises questions about the legality of such a free interpretation of the term "ecosystem". This situation clearly demonstrates that the laws of the digital virtual world are beginning to actively compete with the laws of nature, not only at the level of the ordinary, but also at the level of scientific consciousness.

Attempts to build a new digitallegal reality by analogy with "wellproven" virtual reality, i.e. the shift in emphasis in the law designing from the achievements of legal science to the achievements of information science can lead to a significant emasculation of the so-called human factor, as well as partial or complete disregard of the ethical, axiological and socio-cultural aspects of law. Mechanistic legal development devoid of the very spirit of law can lead to a significant restriction of freedom of will and freedom of choice for subjects of legal relations.

The construction of a system of legal relations according to a simplified model used in virtual reality significantly impoverishes the very idea of law in a close combination of its natural-legal and positivist aspects. Excessive enthusiasm for modern legal science specifically with positivist approaches to legal thinking (the exception is the sphere of constitutional justice, which in all cases exponentially declares adherence to natural legal approaches) has already led to the formation of a negative image of law in public consciousness and understanding it as an "external force enslaving man" and alienated from him (Shapsugov,2016 p. 10).

Ultimately, a new "free" digital world deprived in its idealistic understanding of all the shortcomings of the modern world, in which law is turning into a constantly transforming digital model of optimal behaviour, may well turn out to be even more "hindering" than the existing one.

At the same time, one cannot but agree with the authors who argue that sociological jurisprudence will become even more widespread in the era of legal digitalization. In turn, the sociological approach to cognition and analysis of legal consciousness activates scientific research within the coordinate system of legal anthropocentrism, which asserts that legal reality is constructed by the 
daily actions of subjects of law, and law itself is understood not as a system of norms, but as the constant activity of its subjects to implement legal prescriptions expressed in a sign form and received their certain mental reflection. It is on the subject of law and his legal consciousness that the degree of effectiveness of the regulatory impact of law on public relations will depend (Pashentsev., Alimova,2019 p. 102103).

One cannot but agree that the instruments of legal regulation are changing; and they changing quite actively; however, the self-sufficiency of digital electronic algorithms should not be elevated to a cult, since today all their legal functionality is clearly restricted by the limits of the auxiliary, organizational and provisional functions. Public discussion of the draft law on digital platforms can really stimulate (and it stimulates) increased public attention to the collective solution of legal regulation issues, just as the development of the idea of remote electronic voting; so, theoretically, it can attract a large number of people to exercise their electoral rights.

The widespread development of public political discussion, as well as the widespread development of political and informational virtual platforms independent of the state makes it possible to strengthen control over the functioning of public authorities, making it more open (not voluntarily) and closer to every citizen. However, one should not either overestimate the possibilities of "digital politics". In all cases, the main levers of control over the degree of political freedom remain in the hands of the state, and it is the state that determines the permissible boundaries of political discussion, including based on the national and cultural characteristics of the sociocultural space.

As for the sphere of law enforcement, here we observe how the use of digital algorithms is tied to the implementation of an exclusively auxiliary function, too; in the end, the decision in the case of an administrative offense is made by a person, not a machine. With regret, we have to state that the "alliance" of digital technologies (means of photo-video and other registration) and people in the field of ensuring public order and security has entailed a huge number of law enforcement errors, which shows once again how modern information technologies are far from perfect and that 
occurs when people (law enforcement officers) ignore their direct responsibility to double-check data received by machines. The last remark does not prevent us from considering the urgent problem of "automating the solution of standard legal tasks and performing routine law enforcement procedures". We should agree with the authors who predict in the foreseeable future a decrease in the need for legal specialties, which will affect, among other things, the system of legal education (Shepeleva,2019. p. 65-74).

\section{CONCLUSIONS}

In conclusion, we note the following. The fact that today the law is a traditional regulator of public relations that possesses indisputable authority both at the routine level and at the level of professional legal consciousness, should not diminish in any way the importance and necessity of the most original and innovative research in the field of legal digitalization and digital (artificial) intelligence. It must be admitted that the digitalization of the law making (legislative) and law enforcement processes is fraught with significant dangers along with a rich positive potential. It allows elimination of the negative impact of the "human factor", avoid gaps, collisions, "excessive regulation", judicial errors, violations of the principles of formal equality; these are good goals for the sake of which we should continue to develop the idea of reasonable digitalization of backbone legal processes. However, the associated risks should also not be forgotten. So, for example, the use of digital technologies for recording offenses has not only brought enormous benefits, but also generated a significant number of illegal law enforcement decisions, which already requires understanding at the conceptual and sectoral levels. All this is superimposed with legal nihilism traditional for the domestic legal consciousness and ultimately not only forms the idea of law as an element of coercion and oppression, but also the idea of digitalization of law as another attempt to impose "rules of the game" alien to an individual. Digital interactive law, which some researchers are seriously thinking about, will be much more vulnerable to "attackers" than traditional and, quite likely, will open up even greater opportunities for manipulating public opinion. Giving 
artificial intelligence of even elements of the legal status is a way to avoid legal responsibility for its creators or those who used them in their own interests, etc. Any digital innovation in law can turn into a catastrophe if it is used illconsidered. In this regard, the preservation of traditional methodological guidelines in law will act as one of the most important guarantees of close and mutually beneficial interaction of traditional and innovative digital technologies.

\section{Acknowledgments}

The study was carried out with the financial support of the Russian Foundation for Basic Research within the framework of scientific project No. 18-29-16129.

\section{References}

Baranov P.P., Mamychev A.Yu. Digital transformation of law and political relations: main trends and landmarks // Baltic Humanitarian Journal. 2020. No. 1 (30). P. 357-361.

Mamychev A.Yu., Kim A.A., Frolova E.E. "Future" as an attractor of modern political, legal and socio-economic transformations: an overview of the main problems and approaches // Advances in Law Studies. 2020. Vol. 8. No. P5. P. 317.

Deleuze J. Guattari F. Capitalism and schizophrenia. Book 2. A Thousand Plateaus. Yekaterinburg: U-Factoria; Moscow: Astrel, 2010.892 p.

Delanda M. War in the era of intelligent machines. M.: Cabinet scientist; Institute of General Humanitarian Research, 2014.338 p.

Pasquale F. The Black Box Society: The Secret Algorithms behind Money and Information. Cambridge, MA: Harvard University Press, 2015.

Initiatives of France in the field of robotics. March 2013 // Robopravo. [Electronic source]. Access mode: http://robopravo.ru/initsiativy_frantsii_v _sfierie_robototiekhniki_2013 (access date: 17.02.2020).

Declaration on cooperation in the field of artificial intelligence (04/10/2018) // Robopravo. [Electronic source]. Access mode:

http://robopravo.ru/initsiativy_frantsii_v _sfierie_robototiekhniki_2013_2(access date: 17.02.2020).

Mamychev A.Yu., Miroshnichenko O.I. Modeling the future of law: problems and contradictions of legal policy in the field of normative regulation of artificial 
intelligence systems and robotic technologies // Legal policy and legal life. 2019.No. 2. P. 125-133.

Larina E.S., Ovchinsky V.S. Artificial Intelligence. Big data. Crime. M.: Knizhny mir, 2018. 416 p

Zorkin V.D. Law in the digital world // Rossiyskaya Gazeta. 2018, May 30. [Electronic source]. Access mode: http://alrf.ru/news/pravo-v-tsifrovommire-vystuplenie-valeriya-zorkina-napmyuf/

Kartskhia A.A. Digital imperative: new technologies create a new reality // IS. Copyright and related rights. 2017. No. 8.P. 17 - 26.

The world in the digital age: politics, law, economics in the XXI century: monograph. M $\quad \therefore$ Publishing centre RIOR, 2020.216 p.

Robots claim their rights: doctrinal and legal foundations and moral and ethical standards for the use of autonomous robotic technologies and devices: monograph. Moscow: Publishing Centre RIOR, 2020.349 p.

Greenfield A. Radical technologies: the device of everyday life. Moscow: Delo Publishing House, RANEPA, 2018.424 p.

Baranov P.P., Mamychev A.Yu., Mordovtsev A.Yu. Human rights and freedoms in the digital age: problems and prospects of political and legal dynamics // Baltic Humanitarian Journal. 2019. No. 4 (29). P. 320-324.

Bell D. The coming post-industrial society. A sample of social forecasting. M.: Academia, 2004.944 p.

Borulenkov Yu.P. Legal knowledge and bifurcation of the individual consciousness of a lawyer // Criminalist Library. Science Magazine. 2014. No. 4 (15). P. 366-376.

Berdyaev N.A. The fate of Russia. Experiments on the psychology of war and nationality. Moscow: Philosophical Society of the USSR, $1990.240 \mathrm{p}$.

Ilyin I.A. Our tasks. Articles 1948-1945: in 2 volumes. Vol. 2. M.: Airis-press, 2008.512.

Shchepachev V.A. Constitutional sense of justice as a tool for implementing the provisions of the Constitution of the Russian Federation // Constitutional and municipal law. 2019. No. 5.P. 16-19.

Barinov E.E. Political and legal aspects of constitutional culture // Constitutional and municipal law. 2019. No. 4.P. 10-13. Zorkin V. D. Constitutional and legal development of Russia: monograph / Zorkin V. D. - 2nd edition, revised and enlarged. Moscow: Norma, 2019.448 p. 
Bondar N.S. Harmonization of legal and moral-ethical principles of the Constitution: the practice of constitutional justice // Journal of constitutional justice. 2018. No. 1. P. 615.

Shugurov M.V. The idea of law for the XXI century (on some tasks of modern philosophy of law) // Russian Journal of Legal Research. 2016. No. 2 (7). P. 7886.

Gaivoronskaya Ya. V. Miroshnichenko O.I. Legal problems of digitalization: theoretical and legal aspect // Legal paradigm. 2019. Vol. 18.No. 4. P. 27-34. Nevinsky. V. "Digital rights" of a person: essence, system, meaning // Constitutional and municipal law. 2019. No. 10. P. 26-32.

Yatsenko T.S. Inheritance of digital rights // Inheritance law. 2019. No. 2. P. 11-14.

Kolesnikov. E. V. Development of information rights of citizens in the Russian Federation and the Republic of Kazakhstan: constitutional aspect // Russian justice. 2019. No. 1. P. 13-16. Tanimov O.V., Shevchenko A.R. Digital law: the main essential aspects // Russian justice. 2019. No. 10.P. 6-9.

Gavrilov S.N., Volodina S.I. Information (digital) ecosystem of the legal profession in the context of the digital economy ecosystem of Russia // Actual problems of Russian law. 2019. No. 6. P. 156-166.

Shapsugov D.Yu. The relationship between the science of positive law and the true science of law: another facet of the crisis of legal science // North Caucasian legal bulletin. 2016. No. 1. P. 5-16.

Pashentsev D.A., Alimova D.R. Lawmaking innovations in the context of digitalization of public relations // State and Law. 2019. No. 6. P. 102-106.

Shepeleva O.S. Legal education and training of lawyers: what can foreign experience suggest? // Law. 2019.No. 9.P. 65-74 